\title{
The Network Society, de Jan van Dijk
}

\section{Book Review}

José Luiz de Moura Faleiros Júnior ${ }^{1}$

Jan van Dijk é um renomado professor de sociologia e ciências da comunicação da Universidade de Twente, na Holanda. Em "The Network Society", obra traduzida para o inglês ${ }^{2}$ a partir da publicação original, de 1991, intitulada "De Netwerkmaatschappij" (em holandês), o autor foi pioneiro ao cunhar a expressão "sociedade em rede", que viria a ser redesenhada em 1996 pelo sociólogo espanhol Manuel Castells, em sua obra "The Rise of the Network Society", a primeira parte de uma trilogia denominada "The Information Age".

Embora haja registros de estudos anteriores sobre alguns dos aspectos abordados na obra, van Dijk apresenta um novo conceito ao denominar de "sociedade em rede" a coletividade na qual uma combinação de redes sociais e de mídia dá forma a todos os níveis do modelo sócio estrutural: individual, organizacional e social.

A obra original foi escrita no início da década de 1990, período em que a Internet passou a ganhar popularidade, com potencial de gerar impactos nos três níveis citados pelo autor, o que representaria uma nova gama de desafios interdisciplinares, na medida em que a presença deste novo elemento inter-relacional modificaria, dentre outras coisas, a compreensão que se tinha de privacidade, além de gerar desdobramentos quanto às noções de tempo e espaço.

\footnotetext{
${ }^{1}$ Mestrando em Direito pela Universidade Federal de Uberlândia - UFU. Especialista em Direito Processual Civil, Direito Civil e Empresarial, Direito Digital e Compliance pela Faculdade de Direito Prof. Damásio de Jesus. Graduado em Direito pela UFU.

${ }^{2}$ As traduções da obra de van Dijk para o inglês foram publicadas em três edições: a primeira, em 1999; a segunda, em 2012; a terceira, em 2006.
} 
No curso de sua investigação, van Dijk se dedica ao estudo dos aspectos sociais das novas mídias a partir de diversas frentes. A obra se inicia com uma introdução que fixa premissas e suscita inquietações. Ao tratar de uma possível nova infraestrutura social, o autor se questiona se o advento da Internet representaria uma Segunda Revolução nas Comunicações, à qual atribui a sugestiva denominação de "revolução digital" (VAN DIJK, 2012, p. 6).

Adiante, o autor descreve as características principais das novas mídias e explicita suas capacidades e potenciais para descrever o que denomina de "sistema nervoso" da sociedade em rede. Nessa passagem, o autor faz alusão ao conceito de sociedade em massa (do período moderno) e propõe uma fórmula de transição para o novo modal: a sociedade em rede. Nesse contexto de transição, van Dijk se reporta a uma forma de sociedade que tem as novas mídias como repositórios imprescindíveis para o estabelecimento e para a organização de relacionamentos, e, projetando aquilo que, já em 1991, vislumbrara para o futuro, o autor descreve como essas mídias viriam a complementar ou substituir as comunicações face a face, com a inserção e o predomínio social da tecnologia (VAN DIJK, 2012, p. 19-21; 32-37).

Noutras palavras, o conceito de sociedade em rede, para van Dijk, parte da comparação entre o presente e o futuro da sociedade moderna, a partir da inserção da tecnologia nas relações comunicacionais, sob os três níveis estudados, viabilizando uma aglutinação dos arquétipos interpessoal, organizacional e das comunicações em massa que permitiria trazer "o mundo todo" para dentro das casas e dos ambientes de trabalho graças à Internet, que, paulatinamente, se tornaria elemento nuclear do conceito de sociedade, afetando todos os vieses da vivência coletiva pelo fato de o computador se tornar o modal de interlocução por excelência, ou, em termos mais técnicos, pela inserção social das "CMCs" (computer-mediated communications, ou comunicações mediadas por computador). 
Firme nessa premissa, o autor aborda aspectos técnicos e fundamentais das redes de telecomunicações (VAN DIJK, 2012, p. 19-37), e, em cada um dos capítulos subsequentes, expõe suas visões sobre a influência desse processo de mutação comunicacional em relação aos interesses da sociedade quanto à economia (p. 61-93), à política (p. 95-125), ao direito (p. 127-154), à estruturação social (p. 156-188), à cultura (p. 190-208) e à psicologia (p. 210-238), abordando, ao final, diversas conclusões.

Todas as análises apresentadas nortearam os estudos de Manuel Castells, de 1996, mas, embora este entenda que as redes constituam uma nova morfologia social das sociedades, seu conceito de "sociedade em rede" vai além do conceito de "sociedade da informação", porquanto a mera informação depende de sustentáculos que lhe são trazidos, por exemplo, pela religião, pela elevação cultural, pela organização política e por diversos outros fatores que moldam a sociedade de várias formas (CASTELLS, 2010, p. 469 et seq). Para van Dijk, ao revés, a informação constitui a substância da sociedade contemporânea, que adquire forma a partir das estruturas organizacionais (VAN DIJK, 2012, p. 137 et seq).

Este conceito fundamental, que diferencia o pensamento de van Dijk do de Castells, permite ao autor holandês, em seus capítulos 1 e 3, descrever como os atributos das novas mídias podem alterar as informações padrões em redes sociais, e, para esclarecer este ponto de vista, o autor elucida como a capacidade de armazenamento de dados permite a implementação de um modelo de comunicação assíncrona e de administração de recursos que, somado à natureza interativa das novas mídias, concede aos indivíduos, grupos e organizações o poder de pesquisar e trocar informações de forma independente, sem estar atrelado às unidades centrais de rede.

Nos entremeios desse raciocínio, o autor dedica o capítulo 2 de sua obra à proposição de sete "leis" fundamentais da organização em rede, que destacam como as qualidades da rede definem o efeito das novas mídias na sociedade, na medida em que, por exemplo, quanto mais pessoas entram em 
uma rede, outras desejam se juntar também, o que gera efeitos cascata. E, naturalmente, para garantir o acesso à informação em redes em crescimento, intermediários ${ }^{3}$ se tornam necessários e, para ocupar este relevante posto, o autor descreve como a atenção dos indivíduos se tornará mais seletiva e a luta pelo público será vencida por aqueles que já são populares, fazendo com que as corporações detentoras do poder econômico se tornem ainda mais poderosas. ${ }^{4}$

Os cinco capítulos seguintes, conforme se salientou alhures, são dedicados ao estudo dos impactos dos novos meios de comunicação sobre os domínios sociais mais específicos. No capítulo 4, o autor analisa o fluxo global da economia, em que a produção, a distribuição e o consumo estão conectados a nível empresarial. Prospectando o futuro, o autor analisa o papel das novas mídias no suporte às necessidades de flexibilidade e eficiência das empresas, devido à natureza interativa que ostentam, com potencial de reverter a cadeia de valor, dando aos clientes o poder de alertar as empresas sobre suas demandas.

Para van Dijk (2012, p. 76-81 e 93), as novas mídias também afetam diretamente a economia, através da criação de novas indústrias, os "grandes jogadores", que se esforçam para projetar redes de mídia de acordo com suas oportunidades de negócios, o que denota uma ressignificação da interrelação entre consumidores e fornecedores e do próprio Direito do Consumidor, a partir da ressignificação da economia na sociedade em rede.

O referido aspecto é explorado com maior profundidade no Capítulo 5, que aborda como as novas mídias podem mudar as relações de poder e a própria política. O autor chama de "crença irrealista" (2012, p. 111) a expectativa de que as novas mídias facilitem intrinsecamente a democracia ao mesmo tempo em que dão maiores poderes aos cidadãos ou planificam as

\footnotetext{
${ }^{3}$ Nesta passagem, o autor antecipa o papel das empresas que atuam no segmento das comunicações virtuais e que viriam a constituir o que Tim Wu (2012) denominaria de "impérios da comunicação".

4 O fenômeno da "Googlelização" é muito bem analisado por Siva Vaidhynanathan (2011), em complemento aos apontamentos trazidos por Tim Wu (2012).
} 
estruturas burocráticas. Ao revés, o autor vislumbra como websites de redes sociais e servidores de e-mail são ferramentas de provável utilização para o controle dos cidadãos e para o reforço da formalização e padronização das ações, o que, a depender dos atores centrais, pode fazer com que as novas mídias ampliem e desafiem o poder, acarretando desigualdades e iniquidades sociais.

Nesse ponto, van Dijk (2012, p. 108-112) ainda salienta que as novas mídias devem se dedicar a criar uma hierarquia de trabalhos lastreada em habilidades de mídia, o que significa dizer que a divisão digital não é apenas uma questão de acesso à Internet, mas também de conquista da capacidade de usar novas mídias profissionalmente ou de criar "cultura digital”.

Também neste quinto capítulo, o autor se dedica ao estudo do que chama de "E-Government" e democracia digital, pontuando o seguinte:

Contrariamente às expectativas populares nos anos 90, a Internet não está atraindo mais pessoas para o processo político. [...] Entretanto, ela propicia uma plataforma para formas adicionais de ativismo político que são mais difíceis de realizar no mundo "offline": oportunidades adicionais de se encontrar informações políticas e de criar interação política. Exemplos bastante familiares são o envio e o recebimento de e-mails para e de governos e candidatos, o uso de e-mails para apoiar ou se opor a um candidato, a participação em enquetes virtuais e a participação em discussões online. De longe, a atividade mais popular é a pesquisa e localização de informações sobre partidos políticos ou candidatos, sobre os comportamentos eleitorais dos mesmos, sobre eleições e notícias políticas (VAN DIJK, 2012, p. 106-107). ${ }^{5}$

Indo além desse conceito e propugnando um novo modelo de democracia, van Dijk ainda se debruça sobre as lições de Anouk Zuurmond6 para propor uma transição do paradigma da burocracia para o da

\footnotetext{
${ }^{5}$ No original: "Contrary to popular expectations in the 1990s, the Internet is not drawing more people into the political process. [...] However, it does provide a platform for additional forms of political activity that are more difficult to realize in the offline world: additional opportunities to find political information and to create political interaction. Familiar examples are sending and receiving email to and from the government and candidates, using email to support or oppose a candidate, taking part in online polls and participating in online discussions. By far the most popular activity is browsing to find information about political parties or candidates, about their voting behaviour and about elections and political news."

${ }^{6}$ As informações utilizadas por van Dijk e transcritas em sua obra são extraídas de: ZUURMOND, 1994, p. 300.
} 
"infocracia" após a consolidação da migração da sociedade moderna para a sociedade em rede:

Portanto, uma organização pode criar mais estruturas horizontais, retirando níveis hierárquicos, cancelar checagens e eliminar sistemas-guia devoradores de papel porque a arquitetura informacional pode cuidar dessas coisas. Particularmente, a coordenação (de rotina) e a comunicação (de rotina) estão sendo suplantadas por sistemas da informação. A administração não mais controla essa coordenação e comunicação: procedimentos muito rígidos, criados para guiar tais ações, podem 'desaparecer'. Agora eles estão dentro do sistema (VAN DIJK, 2012, p. 109). ${ }^{7}$

Já em seu capítulo 6, van Dijk também faz averiguação do conceito de poder, mas a partir de uma perspectiva jurídica cujo elemento central para seu entrelaçamento com as redes integradas é a intangibilidade da informação e da comunicação, haja vista serem elementos geograficamente independentes e em constante mudança.

Em suas considerações sobre o impacto dessas novas mídias no Direito, van Dijk destaca que a presença da Internet propicia a facilitação da prática de infrações legais, embora as jurisdições específicas de cada país compliquem ou até inviabilizem investigações, processos e o julgamento dessas infrações (VAN DIJK, 2012, p. 130 et seq).

O autor também analisa os impactos dessa reformulação social quanto ao direito à privacidade, destacando que não se leva em consideração, por exemplo, os desenvolvimentos tecnológicos, como as ferramentas de mineração de dados. Em última análise, posiciona-se no sentido de que os governos e a legislação aplicável a essas novas mídias não têm controle efetivo sobre o conteúdo da Internet, passando a depender da implementação, por parte das corporações, de políticas de Governança de Internet e controle de software (VAN DIJK, 2012, p. 141).

\footnotetext{
7 No original: "Thus, an organization can create more horizontal structures, take out hierarchical levels, cancel checks and eliminate paper-devouring file guiding systems because information architecture can take care of these things. In particular, (routine) coordination and (routine) communication are being taken over by information systems. Management no longer has to control this coordination and communication: very strict procedures, designed to guide these actions, are allowed to 'disappear'. Now they are inside the system".
} 
Em seu capítulo 7, o autor se dedica a analisar como as novas mídias mudam diferentes aspectos da estrutura social. Ele rejeita, por exemplo, a ideia de que as restrições de espaço e tempo são removidas pelas novas mídias, pois, paulatinamente, tais estruturas se tornam multifuncionais e passa a ser ainda mais importante a coordenação do que fazer, em que momento, a fim de garantir a orientação e a rotina funcional da sociedade em rede.

Prosseguindo, tem-se, no capítulo 8, a explicitação de preocupações quanto a um conjunto compartilhado de expressões, artefatos e produtos que são desenvolvidos usando meios pré-programados de novas mídias, o que, para van Dijk, apesar das muitas opções de criação de conteúdo, conduz a preferência da maioria dos usuários ao consumo, em detrimento da produção da cultura digital.

Especulando sobre novas tendências em novos usos das mídias digitais, o autor prevê que o fenômeno de transição propugnado não convergirá para um único meio (a Internet), de modo que esse novo meio não substituirá integralmente os antigos modais midiáticos. Em sua visão, diversidade e contextualização, e não a multifuncionalidade, são os parâmetros que definirão a mídia no futuro.

Em relação às influências da sociedade em rede sobre a psicologia, van Dijk aponta, no capítulo 9, como as novas mídias podem mudar a experiência humana na vida cotidiana, uma vez que a comunicação mediada por computador pode, verbi gratia, influenciar as relações interpessoais.

Seu pensamento é resumido a partir do raciocínio de que a presença da Internet no cotidiano pode tornar os cidadãos dependentes da tecnologia, e, ao mesmo tempo, facilmente controláveis no nível individual. Já no nível dos grupos, os problemas de coordenação surgem nas interações CMC devido a grandes contribuições contrapostas à falta de feedback, de modo que as normas e a liderança precisam se desenvolver com o tempo. Em conclusão, van Dijk argumenta que, em vez de destacar as diferenças entre os contatos 
face a face e virtual (CMC), o papel do pesquisador, neste campo, deve se voltar ao exame da integração das comunicações online e offline.

O derradeiro capítulo da obra de van Dijk é dedicado a revisitar as principais conclusões em termos de implicações e desdobramentos políticos da ascensão tecnológica na sociedade em rede. Destaca-se o acesso universal aos computadores e o desenvolvimento de competências digitais como prioridades absolutas para os governos, que, ainda, devem se atentar às preocupações e precauções contra vulnerabilidades de rede e ataques virtuais, que são eventos inoportunos, mas previsíveis.

$\mathrm{O}$ autor argumenta, ainda, que a Governança de Internet é essencial para que as corporações possam determinar os instrumentais de design e controle da Internet, combinando soluções legais e tecnológicas que garantam higidez a partir da "autorregulação" da comunidade da Internet.

Em síntese conclusiva, nota-se que a ampla abordagem do conceito de "sociedade em rede" proposto por Jan van Dijk causa espanto pela clareza com que, já em 1991, o pensamento de vanguarda do autor lhe permitiu visualizar uma série de desdobramentos sociológicos, econômicos, políticos, culturais, jurídicos e até psicológicos e comportamentais que viriam a se revelar cada vez mais presentes já a partir do início do Século XXI.

As ponderações do autor são recorrentemente reflexivas ao longo do texto e o mesmo sempre se abstém de demonstrar otimismo quanto à interpenetração da Internet na sociedade moderna, denotando seu ceticismo quanto ao potencial dessa ferramenta comunicacional, eis que não a vê como solução para todos os problemas sociais.

Por vezes, o autor demonstra muita riqueza de detalhes técnicos, confirmando seu domínio quanto à compreensão do funcionamento das novas mídias e de seus desdobramentos sobre várias disciplinas. Isso permite uma estruturação alinhada com os campos da sociedade em que a presença da Internet gera efeitos (positivos ou negativos). 
Pela época em que foi escrito, o trabalho de van Dijk é de imperiosa leitura para estudantes, juristas e acadêmicos de humanidades digitais, novas mídias, tecnologias da informação e ciências da comunicação, na medida em que suas ideias foram posteriormente lapidadas por autores emblemáticos como o já mencionado Manuel Castells, tornando o livro um referencial teórico essencial.

Frisa-se, à guisa de conclusão, que a estruturação de "The Network Society" se baseia em modelos teóricos sólidos, mas a linguagem e o estilo didático também tornam a leitura compreensível para interessados que estejam fora da academia, uma vez que todos os capítulos são iniciados por um resumo breve dos tópicos que serão abordados e encerrados com conclusões parciais apresentadas em tópicos elucidativos e claros.

\section{Referências}

CASTELLS, Manuel. The rise of the network society: information age. Vol. 1. 2. ed. Oxford: Blackwell, 2010.

VAIDHYNANATHAN, Siva. A Googlelização de tudo. Trad. Jefferson Luiz Camargo. São Paulo: Cultrix, 2011.

VAN DIJK, Jan. The network society. 3. ed. Londres: Sage Publications, 2012.

WU, Tim. Impérios da comunicação: do telefone à Internet, da AT\&T ao Google. Trad. Cláudio Carina. Rio de Janeiro: Zahar, 2012. 